
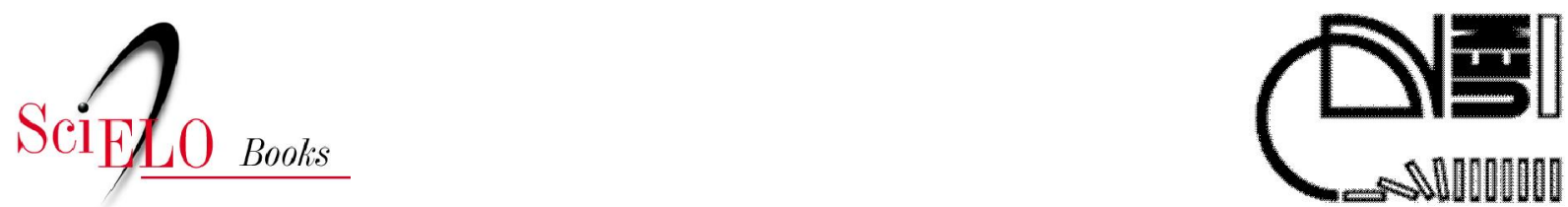

\title{
10 A revolta camponesa de Porecatu
}

\author{
Angelo Priori \\ Luciana Regina Pomari \\ Silvia Maria Amâncio \\ Veronica Karina Ipólito
}

PRIORI, A., et al. História do Paraná: séculos XIX e XX [online]. Maringá: Eduem, 2012. A revolta camponesa de Porecatu. pp. 129-141. ISBN 978-85-7628-587-8. Available from SciELO Books $<\underline{\text { http://books.scielo.org }>\text {. }}$

\section{(1) (1) @()}

All the contents of this chapter, except where otherwise noted, is licensed under a Creative Commons Attribution-Non Commercial-ShareAlike 3.0 Unported.

Todo o conteúdo deste capítulo, exceto quando houver ressalva, é publicado sob a licença Creative Commons Atribuição Uso Não Comercial - Partilha nos Mesmos Termos 3.0 Não adaptada.

Todo el contenido de este capítulo, excepto donde se indique lo contrario, está bajo licencia de la licencia Creative Commons Reconocimento-NoComercial-CompartirIgual 3.0 Unported. 


\section{0}

\section{A revolta camponesa de Porecatu}

\section{Introdução}

Nas décadas de 1940 e 1950, aconteceu, no Estado do Paraná, um conflito de terras de impacto nacional, denominado pela imprensa da época de 'a guerra de Porecatu'. O conflito ocorreu em uma região encravada no extremo Norte do Estado do Paraná, situada no vale do rio Paranapanema. A colonização dessa região começou no final dos anos 1930 e início dos anos 1940, no contexto da nova política de terras, implementada pelo Governo Vargas e conhecida como 'Marcha para o Oeste'.

É dentro desse contexto histórico que posseiros, pequenos proprietários, trabalhadores e colonos vindos, sobretudo, do Estado de São Paulo, atraídos pela perspectiva de conseguir melhores condições de trabalho e de vida e, principalmente, a posse de uma parcela de terra, vão se radicar naquele sertão quase que desconhecido do Norte do Paraná.

Primeiramente, a colonização ocorreu em pequenas posses de terra, por meio do plantio de café, de culturas alimentares e de criação de porcos; posteriormente, em meados dos anos 1940, a organização da propriedade da terra foi realizada com a presença de grandes grileiros, que expulsaram os posseiros e estruturaram as suas propriedades com base no 
cultivo da cultura do café, na criação de gado, na plantação de cana-deaçúcar, associados com o trabalho assalariado.

Portanto, são esses dois agentes sociais - posseiro e grileiro - os personagens de um dos mais importantes conflitos de terra do Estado do Paraná no século XX. A presença desses grandes grileiros na região, que, por meio da polícia, de jagunços e de pistoleiros, expulsavam e tomavam as terras dos posseiros, é que vai motivar a organização de uma resistência - que posteriormente se transformou em resistência armada - com o objetivo de defender as suas posses e benfeitorias nelas existentes.

Os conflitos armados tiveram início no final de 1948 e só foram desmobilizados em julho de 1951, com a presença das tropas da Polícia Militar do Estado e de agentes das Delegacias Especializadas de Ordem Política e Social (DOPS) de São Paulo e do Paraná. A resistência armada dos posseiros de Porecatu marcou a região, que se constituiu em alvo de grandes reportagens nos principais diários do país e em órgãos de imprensa periódica, como a Revista O Cruzeiro e o semanário Voz Operária, órgão do Partido Comunista Brasileiro (PCB).

A intervenção do PCB na região e na organização do movimento armado de Porecatu foi possível pela mudança de sua linha política, decorrente dos 'manifestos' de janeiro de 1948 e de agosto de 1950, que apontavam, para o Partido, a necessidade da defesa da 'violência revolucionária', como linha de ação, visando à luta direta para a tomada do poder. Nesse sentido, o Partido propôs, em seu programa, a formação de uma Frente Democrática de Libertação Nacional, cujo objetivo maior consistia em fazer a 'revolução agrária e antiimperialista'. Em relação ao campo, defendia a imediata entrega das terras dos latifundiários para os camponeses que nelas trabalhavam.

E para isso seria fundamental, na visão do PCB, a organização dos camponeses (pequenos proprietários, posseiros, arrendatários, meeiros, parceleiros) e trabalhadores rurais (assalariados) como aliados naturais do proletariado na tarefa de fazer a revolução. 


\section{As Ligas camponesas}

O embrião da resistência armada dos camponeses de Porecatu tem origem na fundação de Ligas Camponesas na região. A primeira notícia que se tem da formação de uma Liga Camponesa no Estado do Paraná ocorreu em 1944. Nesse ano dois acontecimentos marcaram o início do movimento organizado dos posseiros de Porecatu e região. $\mathrm{Na}$ localidade conhecida como Ribeirão do Tenente, um grupo de 270 famílias fundou uma Liga Camponesa em que foram escolhidos os posseiros Herculano Alves de Barros, Hilário Gonçalves Padilha e José Billar como seus representantes. Em Guaraci, outro grupo de famílias também formou uma Liga, sendo que o representante escolhido para defender os interesses na defesa de suas terras foi o posseiro Manoel Marques da Cunha. Um único objetivo pautou a atuação dessas duas ligas: legalizar a posse da terra (PRIORI, 2011).

Com a saída de Manoel Ribas e a posse do novo governador, (Moisés Lupion, 1946-1950), ficou mais complicada a situação dos posseiros da região. A única garantia que eles tinham para permanecer nas terras era 'frágeis' requerimentos encaminhados ao Departamento de Terras e Colonização do Estado, solicitando a posse dos lotes.

Enquanto a situação se tornava insustentável para os posseiros, as Ligas agiam em defesa dos mesmos, apoiando, organizando e incentivando as centenas de famílias que se preparavam para a luta.

No ano de 1946 houve uma grande manifestação organizada pelas Ligas de Ribeirão do Tenente, Centenário, Guaraci, Água das Pelotas, Cabeceira do Centenário, Água Tupi e Ribeirão do Capim. Mais ou menos 1.500 pessoas, oriundas das mais diversas ligas de toda a região, se reuniram no patrimônio de Guaraci e resolveram fechar a estrada que ligava Presidente Prudente (SP) a Londrina (PR). O objetivo era sensibilizar o governo e os políticos para a situação de instabilidade que vivia a região e pela legalização imediata das terras dos posseiros. 
Essa manifestação, apesar do não cumprimento da promessa de legalização das terras feita pelo representante do Departamento de Terras e Colonização, teve repercussão importante para o movimento dos posseiros. Além de gerar um sentimento de unidade entre os posseiros de toda a região, acabou dando visibilidade para aquele problema que somente era sentido pelos próprios camponeses. Principalmente a população urbana e, sobretudo, os comerciantes iriam tomar conhecimento do litígio e das agruras que viviam aquele povo. E o que é mais importante, despertavase um sentimento de solidariedade com aquela população, que iria ser a tônica de sustentação durante todo o conflito que ali se iniciava.

Tiveram papel importante nesse sentido os parlamentares do PCB, tanto em nível estadual como nacional. Além de criticarem as atitudes políticas de Lupion em não resolver a contenda, condenavam a violência contra os posseiros, exercidas por jagunços e policiais contratados pelos grileiros. O próprio Deputado Carlos Marighella cobrou da Câmara dos Deputados a instalação de uma CPI para apurar as denúncias de violência contra os camponeses de Porecatu.

\section{O PCB toma contato com a região}

O envolvimento do PCB na luta dos posseiros de Porecatu se deu por meio do Comitê Municipal de Jaguapitã, do qual eram dirigentes Arildo, Ângelo, Miguel e Mercedes Gajardoni. A família Gajardoni exerceu papel fundamental na organização do movimento e nos conflitos que se sucederam. Aos poucos, conseguiram organizar os posseiros em grupos, 'conscientizando-os' da importância de defenderem suas posses: primeiro legalmente, depois pelas armas.

Antes mesmo da formação dos grupos armados, que teria início em novembro de 1948, o PCB de Jaguapitã chegou a recorrer ao comitê de Londrina. O farmacêutico, Ângelo Gajardoni, conseguiu levar à região litigada o então vereador londrinense, Manoel Jacinto Corrêa, conhecido 
militante comunista. Jacinto constatou a gravidade da situação e sugeriu, com sucesso, ao comitê estadual do Partido, em Curitiba, um apoio efetivo aos posseiros.

Enquanto em Londrina o PCB iniciava um movimento de solidariedade aos 'resistentes de Porecatu', a família Gajardoni trocava a sua farmácia em Jaguapitã por dez alqueires de terras de mata virgem, nas margens do ribeirão Tenente, possibilitando uma atuação aproximada com os posseiros.

A partir desse momento, diversos militantes do PCB de Londrina passaram a visitar a região com maior frequência, sobretudo o Vereador Manoel Jacinto Corrêa, o advogado Flávio Ribeiro e o médico Newton Câmara, levando roupas, suprimentos alimentares, remédios e dinheiro. Essa ajuda dos comunistas permitiu a conquista da confiança e da simpatia dos posseiros. Com isso se tornaram agentes importantes na orientação da luta e da batalha legal pela posse da terra.

A decisão do Partido Comunista Brasileiro de assumir a organização da luta armada no Norte do Paraná foi concretizada formalmente em novembro de 1948, quando os posseiros aceitaram os argumentos de vários emissários do Partido de que a única saída para a defesa de suas terras era o recurso das armas.

É difícil estabelecer com precisão o que se seguiu imediatamente após a decisão dos posseiros de optarem pela luta armada. Contudo, podemos concluir que o PCB tratou de preparar o terreno para assentar operacionalmente os grupos armados, cujos embriões já existiam, graças ao Comitê Municipal do Partido em Jaguapitã, por meio de Arildo Gajardoni e das Ligas Camponesas formadas em toda a região, sob a liderança de Hilário Gonçalves Pinha.

Mas até esse momento a presença do PCB na área se limitava aos próprios militantes com origem entre os posseiros. Era um grupo bastante reduzido, embora com posições importantes no processo de organização da resistência. Nesse sentido, tanto Arildo Gajardoni quanto Hilário 
Gonçalves Pinha iriam trabalhar com a perspectiva de arregimentar um número cada vez maior de camponeses, visando, de imediato, ao direito à posse legal. $\mathrm{O}$ trabalho de arregimentação era feito de várias formas: por meio de atividades de lazer, como o jogo de futebol, a pescaria, o jogo de truco, que sempre enveredavam para o debate político; e a agenda política, por meio das reuniões das Ligas Camponesas, esse sim, fórum privilegiado da discussão política.

Mas, o interessante é que as próprias Ligas Camponesas, e sabemos, pela inexistência de um aparato legislativo que lhe dessem vida legal, tinha em seus estatutos preocupações de cunho mais social do que propriamente político. Embora a discussão política não estivesse contemplada estatutariamente, era tudo o que se fazia naquelas Ligas.

No final dos anos 1940, o PCB fez circular na região Norte do Paraná uma proposta de estatuto, visando ampliar a discussão em torno da formação de Ligas. Nessa proposta, a orientação era que as Associações de Trabalhadores Rurais fossem constituídas com as seguintes finalidades:

1 Lutar pela educação e cultura dos trabalhadores da região e de suas famílias, por meio de: a) criação de escolas primárias para todas as crianças em idade escolar; b) criação de uma biblioteca circulante, contendo livros instrutivos, principalmente no que se refere à agricultura, criação, organização dos moradores da zona rural e demais assuntos de interesses dos trabalhadores; c) promover festas populares nas ocasiões oportunas, como São João, São Pedro, Santo Antônio, Natal, sete de setembro, primeiro de maio e outras, afim de manter vivas as tradições populares das danças, músicas etc.

2 Lutar quando for preciso, para a obtenção de créditos bancários, para financiamento das plantações e preços compensadores para as colheitas.

3 Conseguir abatimento nas consultas médicas e nos medicamentos, mediante entendimento com o médico e a farmácia.

4 Conseguir salários compensadores para os trabalhadores rurais na derrubada, apanha de café etc.

5 Conseguir estradas (PRIORI, 2011, p. 133-134). 
Se a discussão política pela conquista da terra não estava contemplada claramente, entretanto, alguns pontos eram fundamentais para a vida dos camponeses, como, por exemplo, a luta por créditos bancários, melhores preços para a produção, salários para os trabalhadores das derrubadas, etc. No entanto, implicitamente, o lugar da discussão estava colocado. Não é sem sentido que as comemorações das chamadas festas populares estejam contempladas. Entre elas, o 'primeiro de maio', data que nas décadas de 1940 e 1950 foi significativamente comemorada, fosse por meio dos esperados discursos de Getúlio Vargas, fosse por meio de atividades preparadas pelo Partido Comunista Brasileiro nas mais diversas cidades e regiões do País. Enfim, esses espaços - de lazer e da política - foram fundamentais para trazer o camponês para a luta.

\section{Uma luta, duas frentes}

A resistência camponesa de Porecatu foi realizada em duas frentes: uma, armada, com um grupo reduzido de pessoas, mas com uma disciplina rigorosa e um comando extremamente forte; e outra, legal, composta por algumas centenas de camponeses, nas posses e nas fazendas, além de uma frente de solidariedade e ajuda mútua, nas cidades.

A luta armada estava dividida em três grupos e um Quartel General. Cada grupo estava localizado em uma região estratégica da área conflagrada.

O primeiro grupo ficava sediado na posse de José Billar, às margens do ribeirão Centenário. Esse grupo era chefiado por Arildo Gajardoni, conhecido pela alcunha de 'Strogof'.

O segundo grupo ficava sediado na posse de Hilário Gonçalves Padilha, nas confluências da margem esquerda do ribeirão Tenente com o rio Paranapanema. Esse grupo era liderado por Hilário Gonçalves Pinha, também conhecido como 'Itagiba'. 
E o terceiro grupo, talvez com uma importância menor em relação aos outros dois, estava sediado nas cabeceiras da Água Centenário, ou ribeirão Centenário, e tinha como responsável André Rojo, conhecido como 'Panchito'.

Além desses grupos, havia um Quartel General, cujo comandante era Celso Cabral de Mello, conhecido como 'capitão Carlos', que tinha a função de fazer a ligação com os grupos e com os Comitês Municipais do Partido em Jaguapitã e em Londrina.

Cada grupo era formado por poucos membros, o que demonstra uma participação bastante reduzida de pessoas que se envolveram diretamente no conflito armado. A imprensa da época publicava notícias totalmente equivocadas, superestimando o número de pessoas envolvidas. Havia matérias que falavam de 300 pessoas, outras falavam em 500 e ainda outras, mais exageradas, falavam em milhares de 'camponeses em arma'.

A maioria estava armada de espingarda ou então carabina de 12 tiros. Essas armas eram comuns na região e utilizadas para caça. Mas eram essas as armas de que os camponeses, inicialmente, dispunham. No entanto, essas armas eram muito frágeis. E o resultado prático dessas ações com armas deficitárias era quase que insignificante.

No relatório que elaborou para o Comitê Central do Partido Comunista Brasileiro, Celso Cabral de Mello descreve que as melhores armas em poder dos posseiros eram uma submetralhadora calibre $45 \mathrm{~mm}$ com carregador de 45 tiros, 'em mau estado de funcionamento' e uma submetralhadora de $9 \mathrm{~mm}$, com carregador para 30 tiros, essa 'funcionando regularmente'.

Com o decorrer do tempo, algumas armas mais sofisticadas foram conseguidas, principalmente pistolas automáticas, mosquetões, granadas e metralhadoras, muitas recuperadas dos jagunços ou dos policiais, outras enviadas pelo Comitê Regional do Partido em Londrina.

Todos os membros dos grupos usavam um codinome para se identificar, o que era fundamental para se manter o sigilo e preservar a 
identidade de quem estava de armas na mão. Tanto que, no Processo-crime aberto contra os posseiros que foram à luta armada, alguns não puderam ser indiciados porque não foram identificados. É o caso de 'Machado', ‘Orozimbo' e 'Jordão'.

Os maiores embates dos posseiros se deram, exatamente, contra os jagunços. A Força Policial, por estar fazendo um trabalho para os grileiros, era um inimigo a ser combatido, sem dúvida. Mas era considerado um inimigo fácil. Primeiro porque eram profissionais despreparados para o embate em situação de guerrilha. O máximo que a Força Policial fazia era vasculhar estradas e residências à procura dos posseiros. E, nas estradas, principalmente aquelas que cortavam as florestas, tornavam-se presas fáceis das emboscadas e dos tiroteios de surpresa.

No caso dos jagunços era diferente. Eles não só eram temidos, como conheciam detalhadamente a região e lutavam de igual por igual, às vezes, com as mesmas táticas, às vezes com a mesma precisão. Por isso era fundamental a eliminação dos jagunços. Alguns casos ficaram famosos na região. Primeiro, a eliminação do jagunço Luisinho, que comandava um caminhão de soldados para fazer o despejo da posse de José Billar. No tiroteio decorrente da resistência ao despejo, Luisinho foi morto junto com outros cinco soldados, no sangrento embate que ocorreu no dia 10 de outubro de 1950 (FELISMINO, 1999).

Mas nenhum caso gerou tanto entusiasmo aos posseiros como a vingança e o justiçamento do jagunço José Celestino. A máxima de Luiz Carlos Prestes, expressa em seu Manifesto de Agosto de 1950 (apud VINHAS, 1982, p. 140), de que, para combater a violência dos dominadores, era inevitável e necessário imprimir a violência das massas, foi levada a cabo pelos posseiros de Porecatu. Celestino, cujo nome verdadeiro era José Ferreira de Souza, vinha trabalhando como capanga há vários anos. Contratado pelos grileiros, prestava ainda serviço para a Força Policial do Paraná, da qual, inclusive, tinha a promessa de obter um emprego com a patente de sargento. Celestino era acusado, pelos posseiros, de vários crimes de estupro, despejo e de assassinato. Pelo menos dois posseiros 
foram assassinados por ele: Francisco Bernardo dos Santos e Salvador Ambrósio. Depois desses crimes, os posseiros juraram liquidar com o jagunço.

A orientação de executar Celestino não partiu do PCB. A decisão foi tomada por um grupo de 18 pessoas que estava embrenhado dentro da mata, dentre eles, alguns militantes do PCB, como Arildo Gajardoni e Hilário Gonçalves Pinha. Mas a decisão da execução não partiu do Partido e sim dos próprios posseiros. Mas ela não foi unânime. Quinze posseiros votaram a favor, três se abstiveram.

A morte de José Celestino foi comemorada por toda a região. A população camponesa, "cansada de ser espezinhada e ameaçada pelos jagunços", aplaudiu a coragem daqueles posseiros rebelados. Até a imprensa do PCB deu destaque ao fato. "A justiça camponesa fazia sentir o peso de sua mão sumária e implacavelmente" salientava o editor do Jornal Voz Operária, na edição que publicou matéria sobre o caso.

No dia seguinte, o cadáver de Celestino foi encontrado pelos policiais e carregado para a Vila Progresso, onde lhe deram sepultura. Não houve acompanhantes, mas, por via de dúvidas, um batalhão de 90 soldados teve a incumbência de proteger o enterro.

A repercussão positiva do caso - ao invés do que pensava o comandante Hilário, que achava que um ato como esse poderia repercutir mal - deu novo alento à luta dos posseiros. Centenas de famílias de camponeses, que, até então, achavam que aquele bando de pessoas de armas dentro da mata eram uns aventureiros sem grandes perspectivas, passaram a admirar e a vislumbrar nas ações possibilidades de dias melhores. A luta começou a ganhar popularidade e apoio dos mais variados segmentos da população.

Além da luta armada, na defesa das posses, os posseiros tinham outras reivindicações, como atestam 'os doze mandamentos dos posseiros de Porecatu'. Articulavam as reivindicações pela terra, mas também por melhores salários e condições de trabalho. 
1 Entrega imediata das posses aos seus primitivos ocupantes e entrega, também imediata, dos títulos. Distribuição das terras griladas, das chamadas 'fazendas' e das terras devolutas aos camponeses pobres;

2 Indenização pelo justo valor aos posseiros;

3 Anulação de qualquer processo ou perseguição contra os posseiros e trabalhadores;

4 Remoção da polícia e prisão dos jagunços dos municípios de Porecatu, Jaguapitã e Arapongas;

5 Punição dos assassinos e mandantes dos massacres dos posseiros;

6 Eleição de uma comissão de posseiros para nova divisão das terras;

7 Reconhecimento dos direitos dos trabalhadores do campo;

8 Cr $\$ 3.000,00$ pelo trato de mil pés de café, com direito à planta - Cr\$ 40,00 por saco de 110 litros de café colhido;

9 Pagamento em dinheiro todas as quinzenas;

$10 \mathrm{Cr} \$ 50,00$ livre, por dia de 8 horas de trabalho para os volantes e colonos;

11 Pagamento das férias, inclusive as atrasadas;

12 Para formação de 10.000 pés de café, pagamento de Cr\$3.000,00 com direito de colheita até o quinto ano (PRIORI, 2011, p. 166).

\section{Considerações finais}

O movimento dos camponeses de Porecatu permite-nos repensar a atuação da esquerda no campo, principalmente a atuação do PCB. A atuação desse partido, nos inícios dos anos 1950, foi motivada pela nova linha política formulada pelos manifestos de janeiro de 1948 e agosto de 1950 (PRIORI, 2003).

É verdade que essa linha política teve, internamente, várias resistências. A militância e algumas lideranças, principalmente a sindical, faziam dupla atuação, ora acatando, ora não, a linha política do Partido. 
No caso aqui estudado não foi o Partido quem determinou, por exemplo, a recorrência à luta armada. Embora os documentos apontassem para isso. Quando o Partido chegou à região, a intenção pela luta armada já era uma realidade manifesta. Mas, sem dúvida, essa nova linha política possibilitou uma atuação mais presente do Partido. Assim, o PCB rapidamente se acoplou ao movimento dos posseiros de Porecatu, à sua auto-organização. O que, aliás, naquele momento, foi visto com 'bons olhos' pelos posseiros, como ressaltou, em seus depoimentos, Hilário Gonçalves Pinha.

E por que não houve resistência à ajuda do PCB? Podemos inferir que a história desse partido, sobretudo a experiência acumulada em algumas lutas urbanas, é verdade, tenha contribuído para isso. O PCB podia fornecer tudo o que os camponeses necessitavam para manter o movimento: armas, alimentos, remédios, roupas, dinheiro. Mas, sobretudo, 'quadros' profissionais. A ida do controverso 'capitão Carlos', de 'Machado', de 'Ortiz', de Irineu Luiz de Moraes, de João Saldanha e de alguns dirigentes do Comitê Central é excepcional. Portanto, a ajuda era eficaz.

E o próprio PCB encarava aquele movimento como algo prioritário. Estava ali a possibilidade de se colocar em prática as ideias e as estratégias elaboradas pelos manifestos. De mostrar a eficácia de sua linha política. Não é sem sentido que o principal jornal do partido à época - o $V o$ z Operária - manteve no local do conflito uma equipe de repórteres, desde o mês de novembro de 1950 até praticamente o fim do conflito, em agosto de 1951, como também não é sem sentido a presença de altos quadros da estrutura do PCB (PRIORI, 2003).

Portanto, havia um elo comum de ligação entre os posseiros e o PCB, que permitia essa união. Os posseiros precisavam de uma infraestrutura para manter a luta, o PCB, de um palco para colocar em prática suas estratégias políticas. Essa combinação permitiu uma aproximação entre um e outro. Mas foi uma aproximação momentânea, conjuntural, pragmática. É bem provável que os posseiros não tivessem consciência do significado daquela aproximação, como é bem provável também que o PCB soubesse 
que aquela aproximação poderia se desfazer tão rapidamente como ela foi realizada.

\section{Referências}

FELISMINO, T. A guerra de Porecatu: a história do movimento armado pela posse da terra que sacudiu o Norte do Paraná. Folha de Londrina, Londrina, 14 a 28 jul. 1999.

PRIORI, A. O levante dos posseiros: a revolta camponesa de Porecatu e a ação do Partido Comunista Brasileiro no campo. Maringá: Eduem, 2011.

PRIORI, A. O PCB e a questão agrária: os manifestos e o debate político acerca dos seus temas. In: MAZZEO, A. C.; LAGOA, M. I. (Org.). Coraçoes vermelhos: os comunistas brasileiros no século XX. São Paulo: Cortez, 2003. p. 61-82.

VINHAS, M. O partidão: a luta por um partido de massas. São Paulo: Hucitec, 1982. 